\title{
Counter effect of bee venom and its extracted bradykinin-potentiating factor on acrylamide and chips administration- induced complications in the liver and kidney of male mice
}

\author{
El-Sabry Abu Amra, Fakhr El-Din M Lashein", Amin A Seleem and Amira H Badr
}

\begin{abstract}
Background: Acrylamide has been reported to induce hepato- and nephrotoxicity. The present investigation aims to alleviate the dangerous effects at the histopathological and physiological levels of acrylamide by bee venom and its extracted bradykinin-potentiating factor (BPF). Seventy-five adult male mice were divided into 15 groups: a control (G1) 15 animals for 30 (G1.1), 45 (G 1.2), and 60 (G 1.3) days of experimental periods; acrylamide-administered G2.1, G2. 2, and G2.3 received acrylamide orally (10 mg/kg b.w) daily for 30, 45, and 60 days. Chips-administered G3.1, G3.2, and G3.3 were fed one third of its daily diet by chips for 30, 45, and 60 days. Bee venom- and BPF-treated G4.1 and G4.2 were i.p. injected with bee venom (1.319 mg/kg b.w.) and BPF (2.314 mg/kg b.w.), respectively, day after the other day for 60 days. G5.1 and G5.2 received acrylamide orally (10 mg/kg b.w) combined either with i.p. by bee venom $(1.319 \mathrm{mg} / \mathrm{kg}$ b.w.) or BPF (2.314 mg/kg b.w.) respectively day after the other day for 60 days. G6.1 and G6.2 were fed one third of its daily diet by chips for 60 days combined either with i.p. by bee venom $(1.319 \mathrm{mg} / \mathrm{kg}$ b.w.) or with BPF (2.314 mg/kg b.w.), respectively, day after the other day for 60 days.
\end{abstract}

Results: The results showed that acrylamide administration and chips feeding groups suffer from alteration and histopathological changes in liver and kidney tissues that were accompanied with the increase in liver and kidney physiological biomarker (ALT, AST, urea, creatinine, uric acid) and the decrease in the albumin levels. Acrylamide or chips combined with either bee venom or BPF showed improvement in the level of physiological and histopathological studies.

Conclusion: The study concluded the protective role of bee venom and its extracted BPF against acrylamide- and chips-induced hepato- and nephrotoxicity.

Keywords: Bee venom (BV), Bradykinin-potentiating factor (BPF), Nephrotoxicity, Hepatotoxicity, Acrylamide

\footnotetext{
*Correspondence: flashein@yahoo.com

Department of Zoology, Faculty of Science, Sohag University, Sohag, Egypt
} 


\section{Background}

Acrylamide is soluble in water and polar solvents but insoluble in nonpolar solvents. Acrylamide has properties with high mobility in soil and groundwater (Ashoor \& Zent, 1984 and Eriksson, 2005). Acrylamide has been widely used in various chemical and environmental applications (Davis, Durkin, Howard, \& Saxena, 1976) such as dyes, cosmetics, production and synthesis of polyacrylamides, flocculants in wastewater treatment, and conditioners in soil treatment. The International Agency for Research on Cancer (IARC) has considered acrylamide as carcinogenic to humans (IARC, 1994) based on its carcinogenicity for animal studies. Acrylamide was readily formed when potatoes (carbohydrate-rich food) were heated at temperatures above $120{ }^{\circ} \mathrm{C}\left(248{ }^{\circ} \mathrm{F}\right)$ (Törnqvist, 2005). People were exposed to different amounts of acrylamide mainly through the diet. The World Health Organization (WHO) estimates a daily dietary intake of acrylamide in the range of $0.3-2.0 \mathrm{mg} / \mathrm{kg}$ for the general population (WHO, 2005). Acrylamide is readily absorbed via all routes of administration; acrylamide was found with large quantities in organs having high blood flow such as the muscle, skin, liver, and small intestine (Sipes \& Carter, 1981). Acrylamide is toxic and harmful by all routes of exposure (Smith \& Oehme, 1991). Dietary acrylamide intake may increase the risks of the gastrointestinal tract, liver, and kidney (Benziane, Bouras, Mezaini, Belhadri, \& Benali, 2018; Dortaj, Anvari, Yadegari, Sharifabad, \& Sarcheshmeh, 2017; Mahmood, Amin, \& Salih, 2015; Shrivastava et al., 2018). Acrylamide is also mutagenic and carcinogenic in vitro and in vivo studies (Dearfield et al., 1995; Gamboa da Costa et al., 2003).

The using of natural products has been focused in recent years, as honey bee venom for treatment of different diseases. Honey bee venom is used for self-defense against predators and stored within venom sacs. Bee venom (BV) contains several biochemically or pharmacologically active substances including polypeptides, enzymes, amines, lipids, and amino acids (Chen \& Lariviere, 2010; Danneels, Van Vaerenbergh, Debyser, Devreese, \& de Graaf, 2015; Son et al., 2007). It has been used to treat a variety of diseases and complications such as arthritis, rheumatism, back pain, cancerous tumors, and skin disease $(\mathrm{Tu}, \mathrm{Wu}$, Hsieh, Chen, \& Hsu, 2008; Jang et al., 2009; Lee et al., 2009). Also, bee venom has a curative effect on oxidative stress induced by $\gamma$-irradiation (Elshater, Mohi Eldin, Salman, \& Kasem, 2014) and protective effect against acute pancreatitis (Seo et al., 2008). In addition, several biological properties were reported such as neuroprotection (Khalil, Assaf, ElShebiney, \& Salem, 2015; Yoon \& Lee, 2013), beneficial effects in the treatment of Parkinson disease (Alvarez-Fischer et al., 2013), decrease in the complications of diabetes and multiple sclerosis (Chen \& Lariviere, 2010; Javad, Adeleh, \& Ali, 2014; Orśolić, 2012;
Son et al., 2007), hepatoprotective characteristics (Darwish, El-Bakly, Arafa, \& El-Demerdash, 2013), and anticancer and radioprotective characteristics (Gajski \& Garaj-Vrhovac, 2009; Orśolić, 2012).

The biological and physiological significance of bradykinin-potentiating peptides that were isolated from various toxins of animals was reported in health and disease. Bradykinin-potentiating peptides are small peptides which potentiate the pharmacological effect of bradykinin (Ferreira, Greene, Alabaster, Bakhle, \& Vane, 1970). The action of bradykinin works on inhibiting angiotensin-converting enzyme (ACE), for the regulation of blood pressure (Machado et al., 2015; Verano-Braga et al., 2010). The bradykinin-potentiating factor is considered a useful tool in developing antihypertensive drugs to expand the range of therapies (Lewis \& Garcia, 2003). BPF promotes vasodilation, reduce blood pressures, and increase vascular permeability and vascular exchange (Camargo, Ianzer, Guerreiro, \& Serrano, 2012; Jain, 2003; Sonveaux, 2008). Also, the BPF isolated from scorpion (Buthus occitanus) acts in vivo as a growth factor (Guo, Zhu, \& Wu, 1999; Lipps, 1998), promoting cellular growth responses in the uterus and ovarian follicle (Nassar, Abu-Sinna, \& Abdel Rahim, 1990), and it has a protective effect against cadmium-induced rat liver and kidney damage (Bekheeta, Awadallaa, Salmanb, \& Hassana, 2011). It also mediates prostaglandin release (El-Saadani, 2004; Meki \& Omar, 1997; Needelman, Marshall, \& Sahel, 1975) and stimulates spermatogenesis in premature mice (Nassar, Abu-Sinna, Abdel Rahim, Soliman, \& El-Saadani, 1992). Moreover, Salman (1995) showed that a fraction (BPF) extracted from scorpion venom accelerates burn wound repair. Furthermore, BK acts as a pain mediator and a modulator of animal cell proliferation (Roberts, 1989). The aim of this study is to evaluate the biological significance of bee venom (BV) and its extracted bradykinin-potentiating factor (BPF) against acrylamide of chemical source or carbohydraterich food overheating-induced complications in the liver and kidney of male mice.

\section{Methods \\ Chemicals}

Acrylamide was obtained commercially from Sigma chemical company St. Louis, USA. Bee venom of Apis mellifera was obtained from the Faculty of Agriculture, Assiut University, Egypt. BPF was isolated from bee venom according to the chemical methods of Ferreira (1965).

\section{Experimental design and processing}

Seventy-five male albino mice, Mus musculus, weighing approximately 20-25 g were brought from the farm of Zoology Department, Sohag University, Egypt. Animals were kept in the laboratory under normal conditions of 
light, temperature, and humidity with access of food and water. Animals were classified into a control (G1) represented with 15 animals for experimental periods 30 (G 1.1), 45 (G 1.2), and 60 (G 1.3) days, 5 animals each, acrylamide administered (G2) that was subdivided into three sub-groups (5 mice each) which received acrylamide orally (10 mg/kg b.w) daily for 30 (G2.1), 45 (G2.2), and 60 (G2.3) days. Chips-administered group (G3) was subdivided into three sub-groups which were fed one third of its daily diet by chips for 30 days (G3.1), 45 days (G3.2), and 60 days (G3.3). Bee venom- and BPF-treated groups (G 4.1, G 4.2) were treated i.p. by bee venom (1.319 mg/kg b.w.) (G4.1) and BPF $(2.314 \mathrm{mg} / \mathrm{kg}$ b.w.) (G4.2), respectively, day after the other day for
60 days. The fifth group (G5) was subdivided into two groups which received acrylamide orally $(10 \mathrm{mg} / \mathrm{kg}$ b.w) combined either with i.p. by bee venom $(1.319 \mathrm{mg} / \mathrm{kg}$ b.w.) (G5.1) or BPF (2.314 mg/kg b.w.) (G5.2), respectively, day after the other day for 60 days. The sixth group (G6) was subdivided into two groups which were fed one third of its daily diet by chips for 60 days combined either with i.p. by bee venom (1.319 mg/kg b.w.) (G6.1) or with BPF (2.314 mg/kg b.w.) (G6.2), respectively, day after the other day for 60 days. This study was approved by the Social Science Ethical Committee of the Faculty of Science, Tanta University, and complied with the Egyptian Code of Conduct for Scientific Practice, National Research Centre, Egypt.

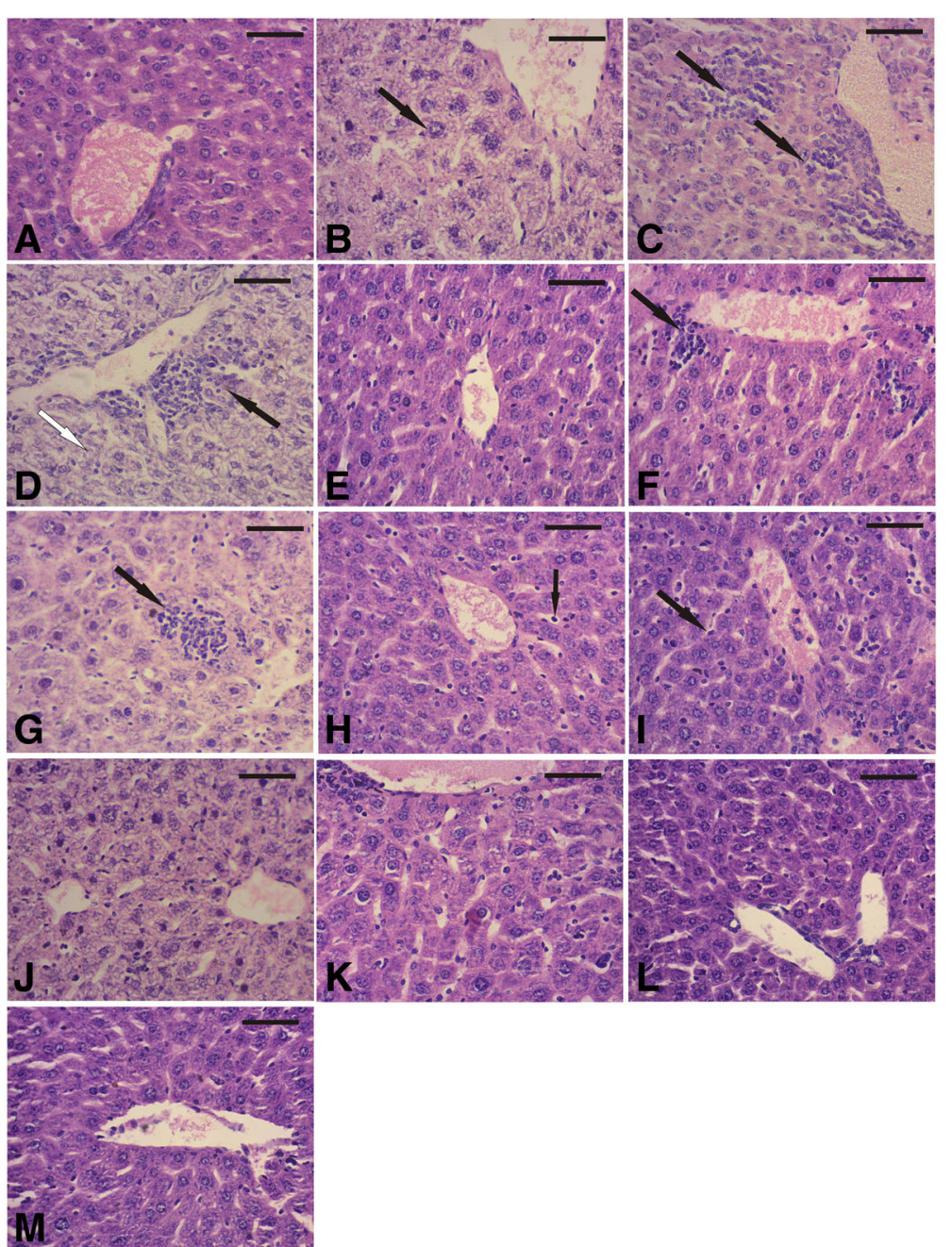

Fig. 1 Photomicrographs of liver sections of the control group (a). Acrylamide-administrated groups 30, 45, 60 days (b-d) showing increased inflammatory infiltrated cells and necrosis of cells accompanied with pyknosis of cell nuclei as compared with the control group. Chips feeding groups at 45 and 60 days $(\mathbf{f}, \mathbf{g})$ showing increased inflammatory infiltrated cells and necrosis of cells with pyknosis of cell nuclei as compared to the chips feeding group at 30 days (e). Bee venom-treated (h) or BPF-treated (i) groups at 60 days showing the similar structure as observed in the control. Acrylamide-administrated groups treated with either bee venom (j) or BPF (k) showing improvement in the form of decreased inflammatory infiltrated cells. Chips feeding groups treated with either BV (I) or BPF (m) showing improvement in the histological architecture as compared with chips feeding groups. H\&E stain scale bar $10 \mu \mathrm{m}$ 


\section{Histological, histochemical, immunohistochemical, and biochemical studies}

All animals in studied groups were anesthetized, sacrificed, and dissected for liver, kidney, and plasma sampling at 30, 45, and 60 days of experimentation. Blood samples were taken from control and the different experimental groups in heparinized tubes for biochemical investigation. The livers and kidneys of studied groups were fixed in carnoy's fixative, dehydrated in ethyl alcohol, cleared in methyl benzoate, and embedded in paraffin wax at $60{ }^{\circ} \mathrm{C}$ for sectioning. The sections were mounted on slides and stained with hematoxylin and eosin and periodic acid Schiff's (PAS) for general histology and carbohydrate detection (Drury \& Wallington, 1976). Sections were dehydrated in ascending grades of ethanol, cleared in xylene, and mounted with DPX. For immunostaining of cytochrome $\mathrm{C}, 7 \mu$ thick of paraffin wax sections of the livers and kidneys of studied groups were mounted on Superfrost/Plus glass slides. The slides were deparaffinized in xylene, rehydrated in ascending series ethanol, and retrieved for re-antigenicity using a $10-\mathrm{mM}$ citrate buffer at $\mathrm{pH} 6$ in $100{ }^{\circ} \mathrm{C}$ for an hour (Buchlowalow \& Bocker, 2010). According to the manufacture protocol of Spring Bioscience company, the sections were treated for 10 min with hydrogen peroxide block and protein block then incubated with primary antibody against cytochrome $\mathrm{C}$ at dilution (1:100) (mouse monoclonal antibody, Santa Cruz, Biotechnology, INC., Germany) for $3 \mathrm{~h}$ at room temperature. Sections were then washed using phosphate buffer $(\mathrm{pH}=7.4)$ and incubated with secondary antibody (Biotinylated Goat Anti-polyvalent HRP DAB detection system, Spring

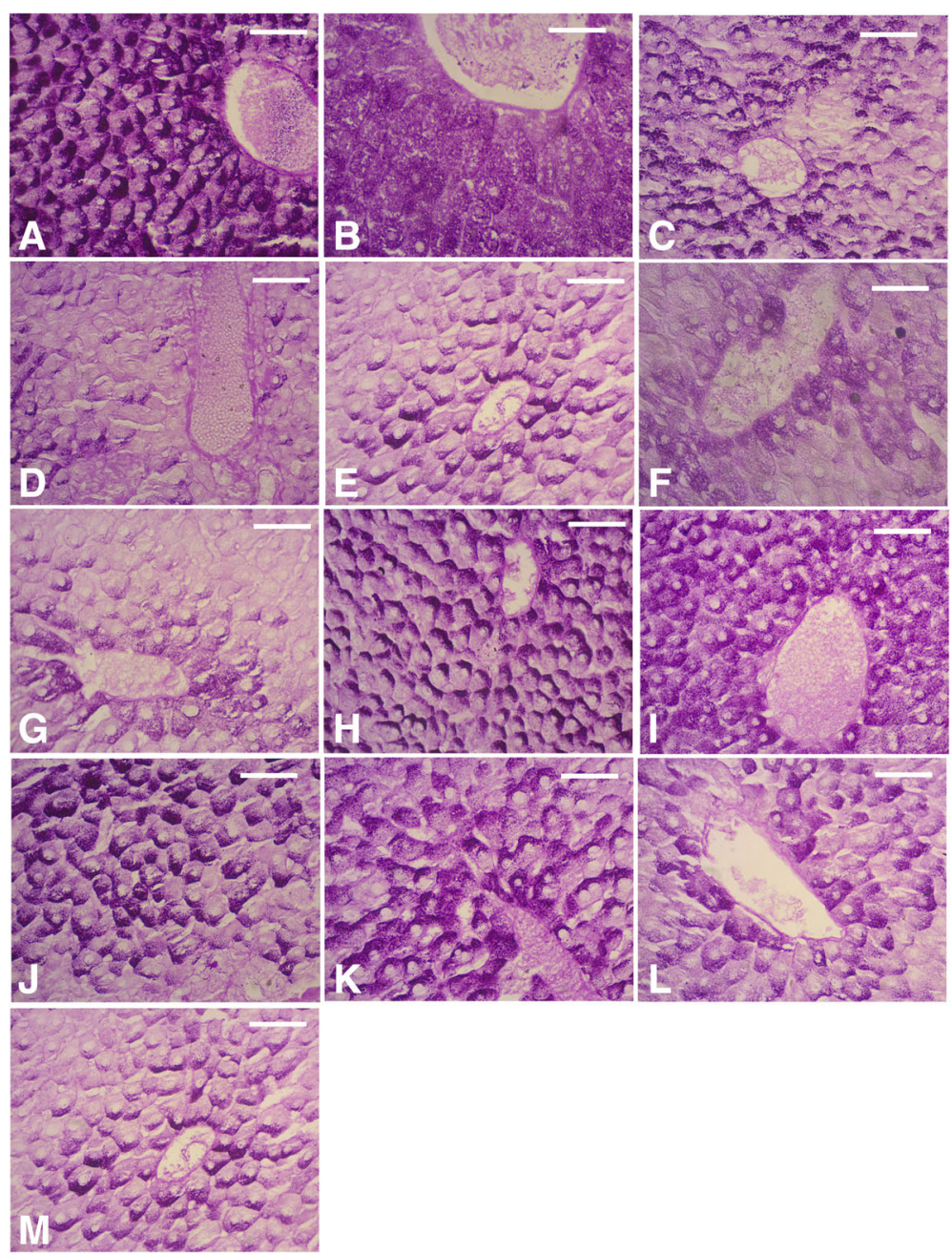

Fig. 2 Photomicrographs of PAS-stained liver sections of the control group (a). Acrylamide-administrated groups along the experimental periods (b-d) showing a decrease of carbohydrate contents. The chips feeding groups at 30, 45, and 60 days (e-g) showing a decrease in the carbohydrate contents as compared with the control group. Bee venom-treated (h) and BPF-treated (i) groups at 60 days of treatment showing similarity to the control. Acrylamide-administrated groups treated with either BV (j) or BPF (k) showing improvement of carbohydrate contents. Chips feeding groups treated with either BV (I) or BPF (m) showing improvement in the carbohydrate contents. PAS staining scale bar $10 \mu \mathrm{m}$ 
Bioscience, Pleasanton, USA). DAB and chromogen were mixed to visualize the color of reaction. Sections were dehydrated, cleared, and mounted. Selected sections at the level of histological and immunohistochemical were photographed and processed as required.

Biochemical investigation for the liver function was assessed by determination of the activities of ALT/GPT, AST/GOT, and albumin in plasma. The kidney function was assessed by determination of the activities of urea, uric acid, and creatinine in plasma. These parameters were performed spectrophotometrically using available specific kits. The activities of enzymes in plasma were estimated according to the method of Reitman and Frankel (1957). Albumin level in plasma was measured according to Doumas and Biggs (1976). The activity of creatinine level in plasma was measured according to Husdan and Rapoport (1968). Urea in plasma was measured according to Chaney, Marbach, and Fawectt (1962). Uric acid in plasma was measured according to Barham and Trinder (1972). The results are presented as means \pm SE. Student's $t$ test was used, and the results were considered significant at $P^{<} 0.05$.

\section{Results \\ Histological, histochemical, and immunohistochemical results of the liver}

Histological examination of hematoxylin and eosin-stained sections of control group revealed the normal architecture of the liver; the cells are arranged in cords that interspersed with sinusoids (Fig. 1a). In acrylamide-

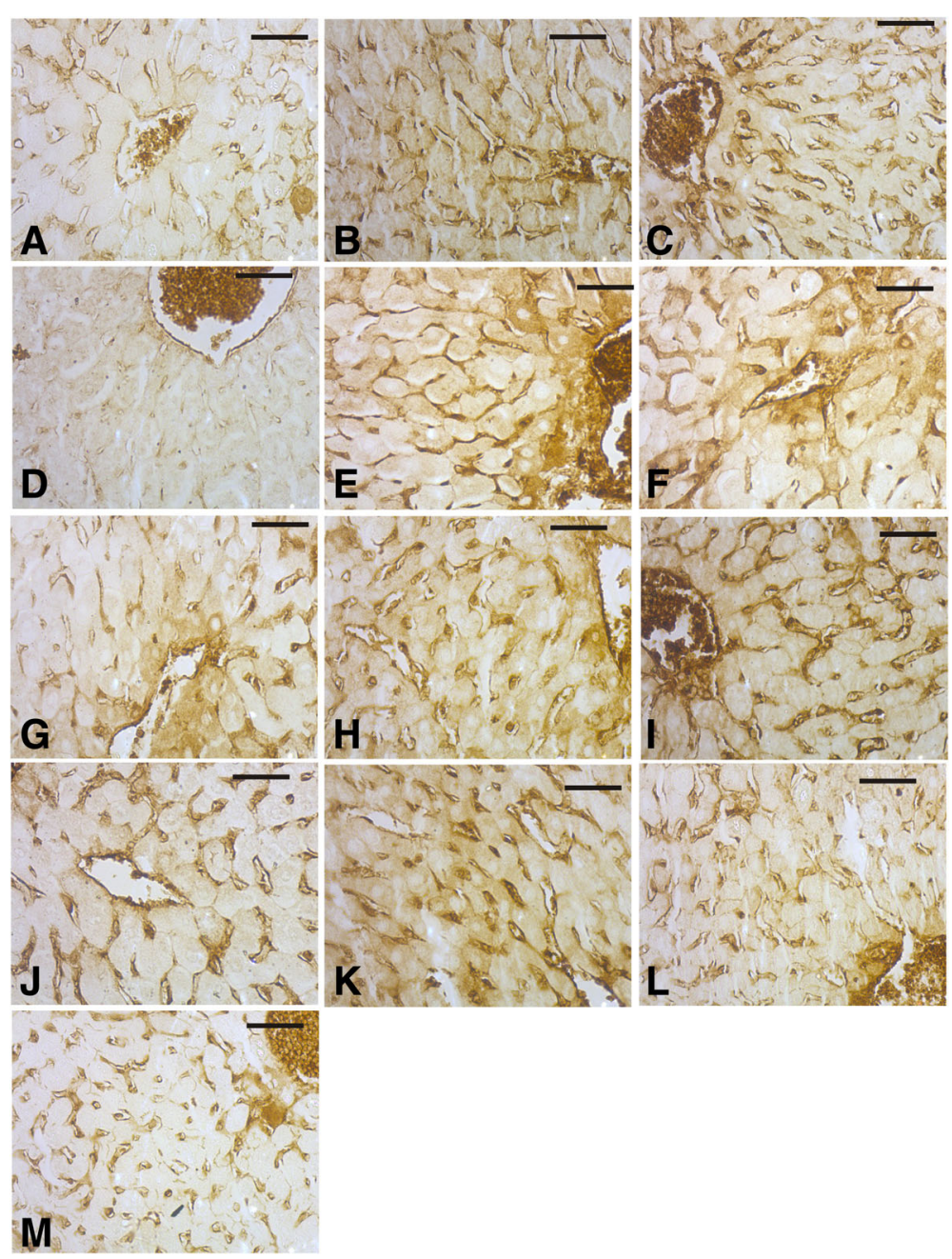

Fig. 3 Photomicrographs of immunohistochemistry of cytochrome $C$ in liver sections of the control group (a). Acrylamide-administrated groups showed decrease in the expression at 60 days (d) in contrast to the elevated expression at 30 and 45 days (b, c). Chips feeding groups at 30, 45, and 60 days (e-g) showed elevated expression. BV-treated group (h) at 60 days showed higher cytochrome C expression compared to the control. BPF-treated group (i) showing an increase of cytochrome C expression. Acrylamide-administrated group treated with either BV (j) or BPF (k) showing improving downregulated expression of cytochrome C compared to acrylamide administration at 60 days. Chips feeding group treated with either BV (I) or BPF (m) showing the normal expression that was mostly similar to the control. Immunostaining of cytochrome C scale bar $10 \mu \mathrm{m}$ 
administrated groups along the experimental periods, the liver showed altered nuclei, hypertrophy (Fig. 1b) to pyknosis in a dose-dependent manner (Fig. 1c, d) as compared to control. In chips feeding groups, time-dependent effects were also observed. Inflammatory infiltrated cells and necrosis of cells accompanied with pyknosis of cell nuclei were noted in chips feeding groups for 45 and 60 days (Fig. 1f, g) as compared to the feeding group for 30 days (Fig. 1e), respectively. In both the bee venom and the bradykinin-potentiating factor (Fig. 1h, i), treated groups showed similarity to the control group. Acrylamide-administrated groups with either bee venom (Fig. 1j) or bradykininpotentiating factor (Fig. $1 \mathrm{k}$ ) treatments along the experimental periods showed improvement in the form of markedly decreased inflammatory infiltrated cells, necrosis, and pyknosis of cell nuclei as compared with acrylamide-administrated groups. The chips feeding groups treated with either bee venom (Fig. 11) or bradykinin-potentiating factor (Fig. 1m) showed improvement in the histological architecture as compared with chips feeding groups.

Histochemical examination of PAS-stained sections of the liver showed normal carbohydrate contents in the control group (Fig. 2a). Depletion of carbohydrate contents was noted in PAS-stained sections of acrylamide-administrated groups from 30 to 60 days of administration (Fig. 2b-d) as compared to control. In chips feeding groups (Fig. 2e-g), time-dependent effects were also observed. A decrease in the carbohydrate contents was noted as compared to the control group. The bee venom-treated (Fig. 2h) and the bradykinin-potentiating factor-treated (Fig. 2i) groups showed normal carbohydrate contents similar to control. Acrylamide-administrated groups treated with either bee venom (Fig. 2j) or bradykinin-potentiating factor (Fig. 2k) showed improvement in the carbohydrate contents as compared to acrylamide-administrated groups. Also, chips feeding groups treated with either bee venom (Fig. 2l) or bradykinin-potentiating factor (Fig. $2 \mathrm{~m}$ ) showed improvement in the carbohydrate contents as compared to chips feeding groups.

Immunohistochemical staining of cytochrome $\mathrm{C}$ for selected groups showed its normal expression in the blood sinusoids of control group (Fig. 3a). The expression of cytochrome $\mathrm{C}$ in acrylamide-administrated groups at 30 and 45 days of treatment revealed an increase in the expression (Fig. 3b, c), respectively, but the administration of acrylamide for 60 days provoked inhibition of cytochrome $\mathrm{C}$ expression (Fig. 3d). The expression of cytochrome $\mathrm{C}$ was noted in chips feeding groups at 30 and 45 days (Fig. 3e, f) and still expressed up to 60 days of chips feeding (Fig. 3g) as compared to acrylamide administration for a similar period (Fig. 3d). The increased expression of cytochrome $\mathrm{C}$ was observed in the liver of bee venom-injected groups (Fig. 3f) as compared to both the control and acrylamide-administrated groups. The Bradykinin-potentiating factor-treated group at 60 days of treatment showed also increase of cytochrome $\mathrm{C}$ expression (Fig. 3i) compared to the control group. Acrylamide-administrated groups treated with either bee venom (Fig. 3j) or bradykinin-potentiating factor (Fig. 3k) along the experimental periods showed improvement of downregulated expression of cytochrome $\mathrm{C}$ compared to the acrylamide-administrated group. Also, chips feeding groups treated with either bee venom (Fig. 3l) or bradykinin-potentiating factor (Fig. $3 \mathrm{~m}$ ) showed normal expression and distribution of staining that was mostly similar to control.

Table 1 Effect of acrylamide and chips administration on the plasma GOT (U/ml), GPT (U/ml), and albumin (g/dl) of mice at 30 and 45 days of administration

\begin{tabular}{|c|c|c|c|c|c|}
\hline & & & Control & Acry. & Chips \\
\hline \multirow[t]{4}{*}{$\overline{\mathrm{GOT}}$} & 30 days & Mean \pm SE & $89.4 \pm 6.00$ & $146.76 \pm 9.44^{* *}$ & $93.8 \pm 4.02$ \\
\hline & & $\%$ of change & & +64.16 & +4.92 \\
\hline & 45 days & Mean \pm SE & $93 \pm 4.08$ & $141.7 \pm 19.92^{*}$ & $119 \pm 8.66^{*}$ \\
\hline & & $\%$ of change & & +52.36 & +27.95 \\
\hline \multirow[t]{4}{*}{ GPT } & 30 days & Mean \pm SE & $99 \pm 7.23$ & $130 \pm 3.42^{*}$ & $132.4 \pm 4.6^{*}$ \\
\hline & & $\%$ of change & & +31.31 & +33.33 \\
\hline & 45 days & Mean \pm SE & $105.4 \pm 7.46$ & $137.2 \pm 3.22^{*}$ & $141.6 \pm 8.51^{*}$ \\
\hline & & $\%$ of change & & +30.17 & +34.34 \\
\hline \multirow[t]{4}{*}{ Albumin } & 30 days & Mean \pm SE & $3.38 \pm 0.174$ & $3.262 \pm 0.07$ & $3.588 \pm .075$ \\
\hline & & $\%$ of change & & -3.49 & +5.58 \\
\hline & 45 days & Mean \pm SE & $3.48 \pm 0.149$ & $3.04 \pm 0.022^{*}$ & $3.16 \pm 0.14$ \\
\hline & & $\%$ of change & & -12.64 & -9.19 \\
\hline
\end{tabular}

Significance difference between control and administrated groups. $n=5$ 


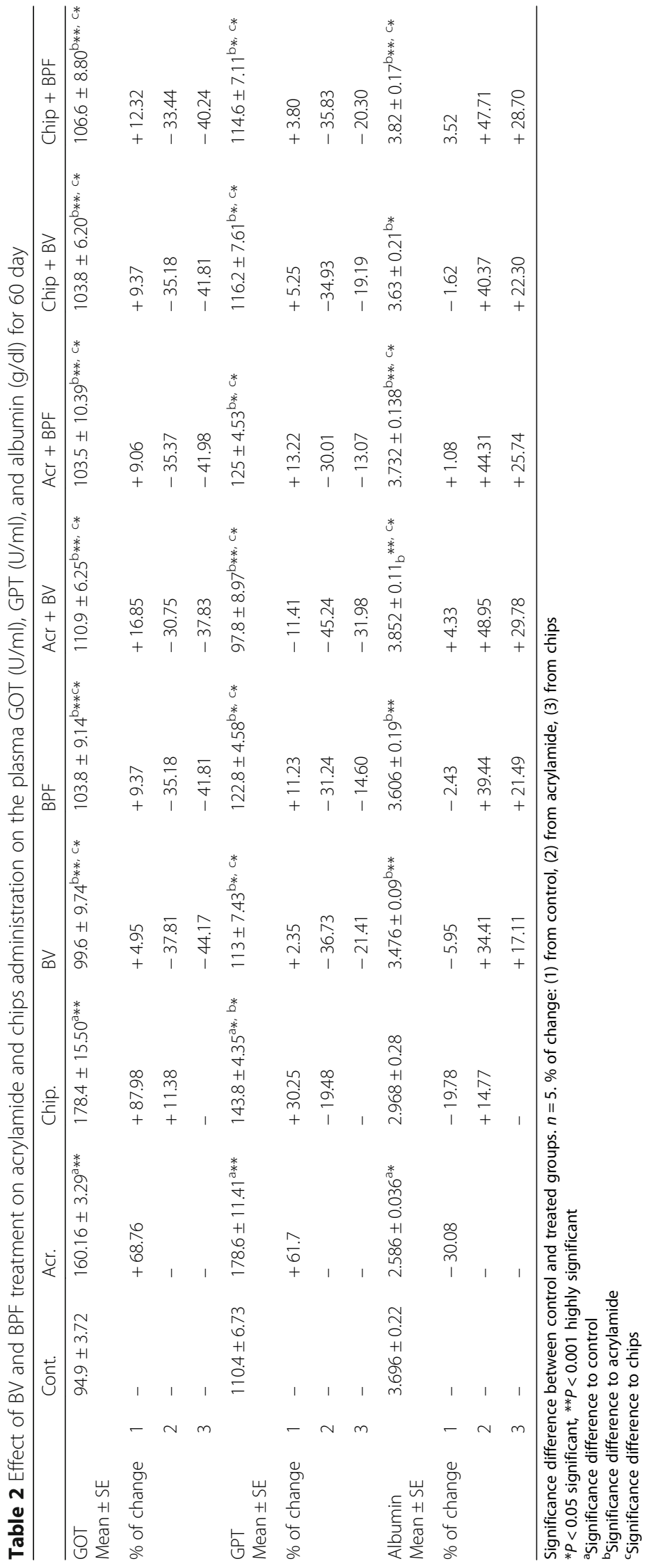




\section{Biochemical observations of liver function}

In plasma, the levels of GOT, GPT, and albumin were severely affected in acrylamide-administered groups from elevation of the enzyme (GOT, GPT) to severe decrease of albumin during the experimental periods as compared to both the control and chips-administered groups (Tables 1 and 2). At 60 days of experimentation, no significant difference in plasma levels of GOT, GPT, and albumin was observed in bee venom-treated or bradykinin-potentiating factor (BPF)-treated groups as compared to the control group (Table 2). The combined acrylamide- or chips-treated groups which received bee venom or BPF after acrylamide or chips administration showed a non-significant change in the levels of plasma GOT, GPT, and albumin as compared with control (Table 2).

\section{Histological, histochemical, and immunohistochemical results of the kidney}

Histological examination of hematoxylin and eosin-stained sections of the kidney of the control group showed normal histological picture of the renal tubules and corpuscles. The acrylamide-administrated groups along the experimental periods were shown to be severely affected at 60 days of administration (Fig. 4d) as compared to the effect at 30 and 45 days of administration (Fig. 4b, c). The effect of acrylamide administration results in squamation of the lining epithelium that leads to a wider lumen of the tubules. In chips feeding groups, time-dependent effects were also observed. At 60 days of administration (Fig 4g), damage of the kidney tubules and inflammatory cell infiltration that accompanied with pyknosis of cell nuclei of the glomeruli

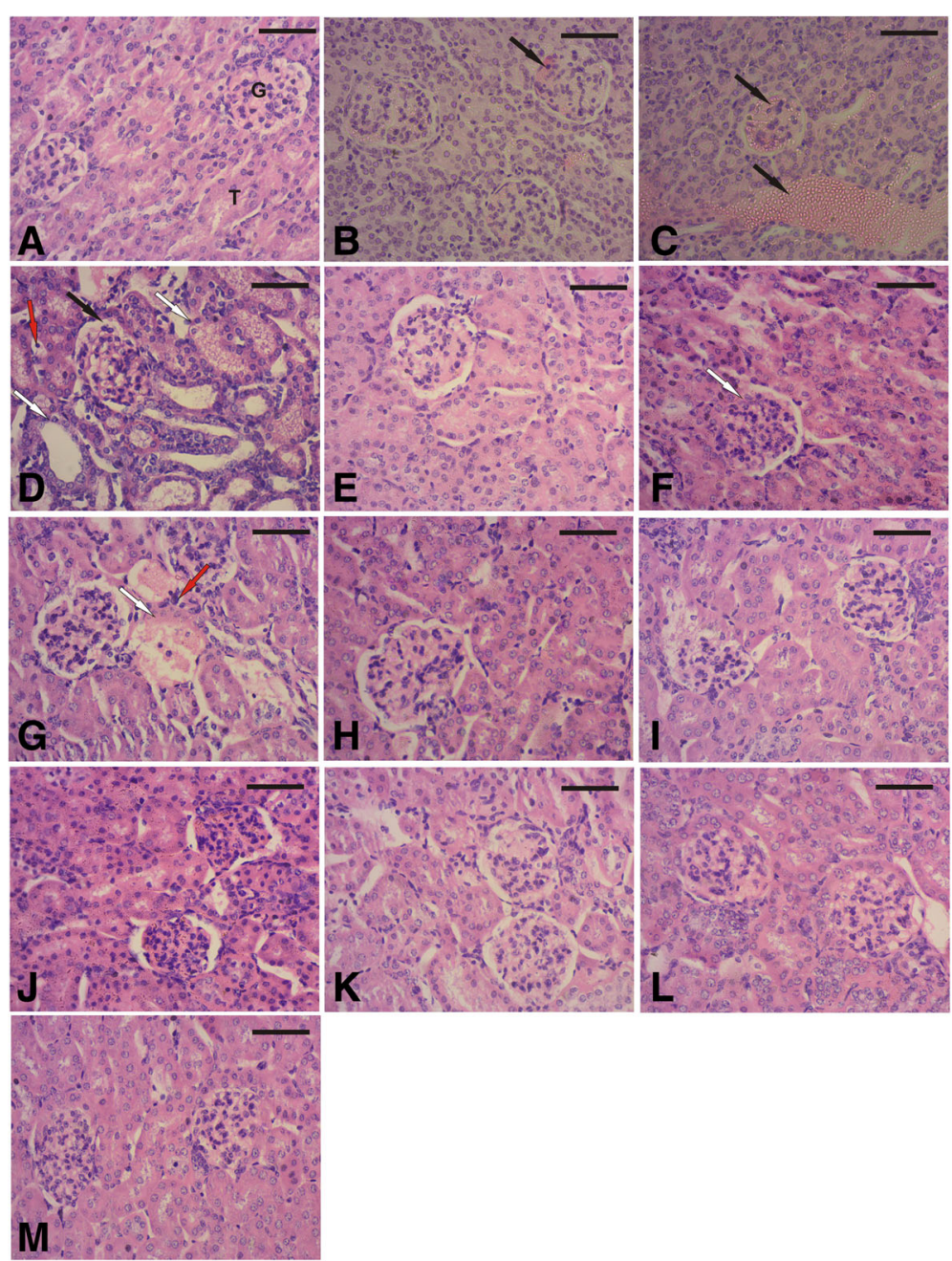

Fig. 4 Photomicrographs of kidney sections of the control group (a). Acrylamide-administrated groups at 30 days (b) and 45 days (c). At 60 days of administration (d) showing squamation of kidney tubules (white arrow) and inflammatory cell infiltration (red arrow). Chips feeding group at 30, 45, and 60 days (e- $\mathbf{g})$ showed damage of the kidney tubules. BV-treated group (h) and BPF-treated group (i) at 60 days showed a similarity with the control group. Acrylamide-administrated groups treated with either BV (j) or BPF (k) showing improvement of the damage tubules as compared to acrylamide-administrated groups. Chips feeding groups treated with BV (I) or BPF (m) showing improvement at the histological level as compared to chips feeding groups. H\&E stain scale bar $10 \mu \mathrm{m}$ 
and kidney tubules were noted as compared to the chips feeding group at 30 and 45 days (Fig. 4 e, f) and the control group (Fig. 4a). In both bee venom-treated (Fig. 4h) and bradykinin-potentiating factor-treated (Fig. 4i) groups, throughout the different periods of study, no histological changes were noted as those observed in either the acrylamide- or chips-administered groups. Acrylamideadministrated groups treated with either bee venom (Fig. 4j) or bradykinin-potentiating factor (Fig. 4k) showed improvement in the form of markedly decrease of tubular damage and shrinkage of the glomerulus as compared to acrylamide-administrated groups. The chips feeding groups treated with either bee venom (Fig. 4l) or bradykinin-potentiating factor (Fig. $4 \mathrm{~m}$ ) showed improvement at the histological level as compared to chips feeding groups.

Histochemical examination of PAS-stained sections showed normal positive reaction in the glomerulus and the brush border of kidney tubular cells in the control group (Fig. 5a). The effects of acrylamide were gradually increased in a time-dependent manner (Fig. 5b-d). The stainability of the kidney tissue concerning the glomeruli and kidney tubular brush border of the lining cells was increased. In chips feeding groups, time-dependent effects were noted. At 60 days of treatment (Fig. $5 \mathrm{~g}$ ), increase in the carbohydrate contents in the glomeruli and tubules was noted as compared to the 30 and 45 days of the feeding groups (Fig. 5e, f) and the control group (Fig. 5a). In both bee

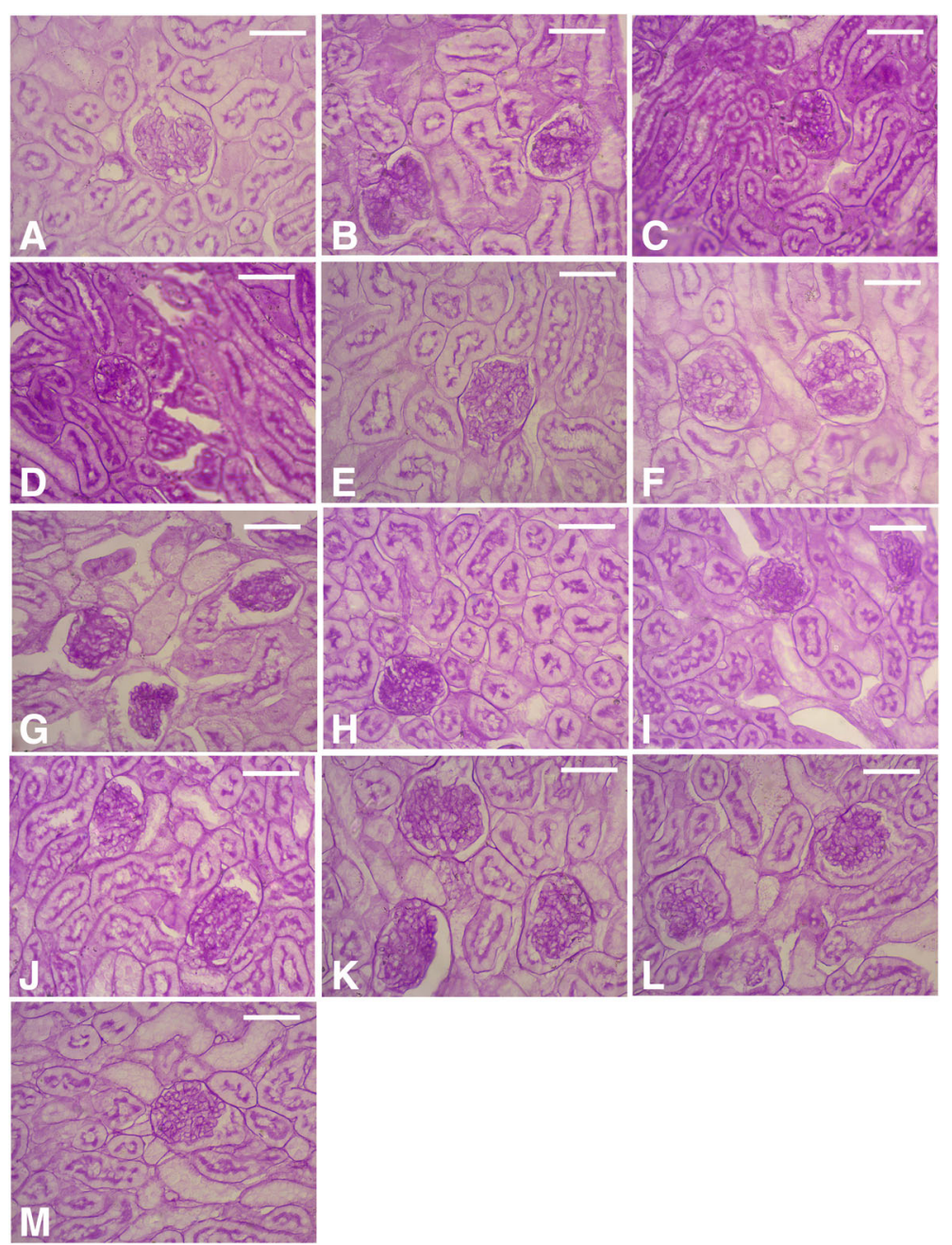

Fig. 5 Photomicrographs of PAS-stained kidney sections showing the normal PAS positivity in the glomeruli and the brush border of kidney tubules in the control group (a). Acrylamide-administrated groups at 30, 45, and 60 days (b-d) showed elevation of carbohydrates in the glomeruli and kidney tubules. Chips feeding group at 30 and 45 days (e, $\mathbf{f}$ ) did not display any change as compared with the control group. At 60 days (g) showed the increase in the carbohydrate contents of the glomeruli and tubules as compared to the control group. BV-treated group (h) and BPFtreated group (i) at 60 days of treatment showed a similarity with the control group. Acrylamide-administrated groups treated with either bee venom (j) or BPF (k) showing improvement of carbohydrate contents. Chips feeding groups treated with either bee venom (I) or BPF (m) showing improvement of carbohydrate contents as compared to chips feeding groups. PAS staining scale bar $10 \mu \mathrm{m}$ 
venom-treated (Fig. 5h) and bradykinin-potentiating factor-treated (Fig. 5i) groups, similar stainability of the glomeruli and kidney tubules was observed as in the control group. Acrylamide-administrated groups treated with either bee venom (Fig. 5j) or bradykinin-potentiating factor (Fig. 5k) showed improvement in the stainability with PAS that looks similar to the control. The chips feeding groups treated with either bee venom (Fig. 5l) or bradykininpotentiating factor (Fig. $5 \mathrm{~m}$ ) showed improvement in carbohydrate contents as compared to chips feeding groups.

Immunohistochemical staining of cytochrome $\mathrm{C}$ for selected groups showed its normal expression in the control group (Fig. 6a) as it is detected in the glomeruli, proximal tubules, and intertubular connective tissue. The expression of cytochrome $\mathrm{C}$ in acrylamide-administrated groups at 30,45 , and 60 days of administration provoked inhibition of the expression in a time-dependent manner (Fig. 6b-d), respectively. The expression of cytochrome $\mathrm{C}$ in chips feeding group at 30, 45, and 60 days (Fig. 6e-g) did not show any disturbance in expression as compared to the control. The decreased expression of cytochrome $\mathrm{C}$ was observed in the kidney of bee venom-injected groups (Fig. 6h) and in the bradykinin-potentiating factor-treated group (Fig. 6i) as compared to both the control and acrylamide-administrated groups. Acrylamide-administrated groups treated with either bee venom (Fig. 6j) or bradykinin-potentiating factor (Fig. 6k) along the experimental periods showed improvement of downregulated expression of cytochrome $\mathrm{C}$ that returned to a normal pattern as compared to acrylamide-administrated group. Chips

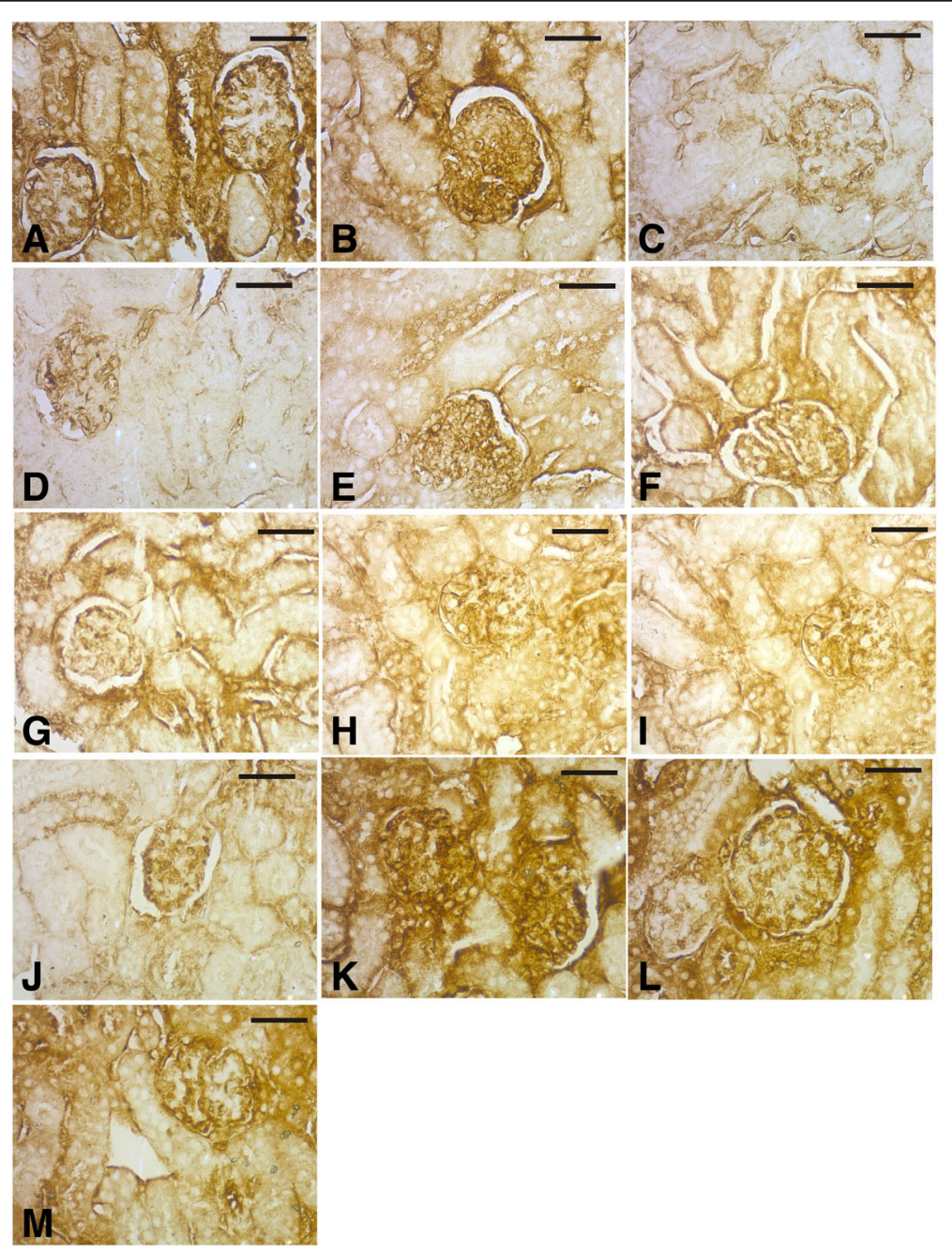

Fig. 6 Photomicrographs of immunohistochemistry of cytochrome C in kidney sections of the control group (a). Acrylamide-administrated groups showed the decrease in expression at 30, 45, and 60 days (b-d). Chips feeding groups at 30, 45, and 60 days (e-g) showed slight downregulated expression compared to the control. BV-treated group (h) and BPF-treated group (i) at 60 days showed downregulated expression of cytochrome $\mathrm{C}$ as compared to the control. Acrylamide-administrated groups treated with either BV (j) or BPF (k) showing improvement of downregulated expression of cytochrome C compared to acrylamide administration. Chips feeding groups treated with either BV (I) or BPF (m) showing the normal expression and distribution of staining that was mostly similar to the control. Immunostaining of cytochrome C scale bar $10 \mu m$ 
feeding group at 60 days treated with bee venom (Fig. 6l) or bradykinin-potentiating factor (Fig. $6 \mathrm{~m}$ ) showed normal expression and distribution of staining that was mostly similar to the control.

\section{Biochemical observations of kidney function}

In plasma, the levels of creatinine, urea, and uric acid were time-dependently increased in the acrylamide- and chips-administered groups as compared to the control (Tables 3 and 4). At 60 days of experimentation, there was no significant difference in plasma creatinine, urea, and uric acid in groups injected with bee venom (BV) or bradykinin-potentiating factor (BPF) compared with the corresponding control group (Table 4). Moreover, the combined treatment of acrylamide or chips with bee venom or BPF showed a significant improvement in the plasma creatinine, urea, and uric acid as compared with acrylamide- or chips-administered groups (Table 4).

\section{Discussion}

In the liver, acrylamide- and chips-administered groups revealed liver complications at both histological, immunohistochemical, and biochemical investigations. Cell vacuolation, nuclear pyknosis, inflamatory cell infiltration, and cytochrome c induction, those accompanied with elevated liver enzymes and depressed albumin in plasma, were observed in a time-dependent manner. Vacuolation of hepatocytes as ballooning degeneration is considered as the cellular defensive mechanism against injurious elements (Abdel Hameed, 2004), and these vacuoles are responsible for collecting the injurious substances and preventing them from interfering with the biological activities of these cells (Cheville, 2009). Similar results have demonstrated that the severity of the lesions that causes hepatotoxicity by acrylamide increases with the doses of acrylamide (AL-Mosaibih, 2013; Osman, Romeilah, Elgammal, Ramis, \& Hasan, 2016). Moreover, disruption of the pattern of hepatic cords, the incidence of necrosis, congestion of blood vessels, lymphocyte infiltration, inflammation, and vacuolization of hepatocytes were reported in rats exposed to acrylamide (Osman et al., 2016; Siahkoohi, Anvari, Tafti, \& Sharifabad, 2014). The cytoplasmic vacuolization of the hepatic cells was attributed to the progressive ischemia, lipid accumulation, and hypoxia in the cells (Abdul-Hamid \& Moustafa, 2005; Moustafa \& Abdul-Hamid, 2007). Yousef and El-Demerdash (2006) suggested that the cellular destructed lysosomes facilitate the process of autolysis in acrylamide-administered rats. In addition, acrylamide generates reactive oxygen species (ROS) which enhanced lipid peroxidase production; cellular fatty acids are readily oxidized by ROS to produce lipid hydroxides and lipid peroxyl radicals (Rice-Evans \& Burdon, 1993).

The current study showed that the administration of acrylamide of a chemical or from an overheated carbohydrate-rich food provoked a significant increase in the plasma enzyme marker of hepatocellular injury (AST/GOT) and (ALT/GPT) that coincides with previous studies (Osman et al., 2016; Rawi, Marie, Fahmy, \& El-Abied, 2012). Acrylamide increases the degree of membrane permeability of the liver and induces cellular transformation (Awad, Abdel-Rahman, \& Hassan, 1998). Therefore, the disruption of these membranes during hepatocellular damage may cause the translocation of liver enzymes ALT and AST into the blood where biochemical changes coincide with histopathological alteration in liver tissues as reported by Pari and Murugan

Table 3 Effect of acrylamide and chips on the plasma creatinine $(\mathrm{mg} / \mathrm{dl})$, urea $(\mathrm{mg} / \mathrm{dl})$, and uric acid $(\mathrm{mg} / \mathrm{dl})$ of mice at 30 and 45 days of administration

\begin{tabular}{|c|c|c|c|c|c|}
\hline & & & Control & Acr. & Chips \\
\hline \multirow[t]{4}{*}{ Creatinine } & 30 days & Mean \pm SE & $0.794 \pm 0.04$ & $1.72 \pm 0.19^{* *}$ & $2.148 \pm 0.08^{* *}$ \\
\hline & & $\%$ of change & & +116.62 & +170.52 \\
\hline & 45 days & Mean \pm SE & $0.814 \pm 0.043$ & $2.254 \pm 0.28^{* *}$ & $2.214 \pm 0.25^{* *}$ \\
\hline & & $\%$ of change & & +176.90 & +171.99 \\
\hline \multirow[t]{4}{*}{ Urea } & 30 days & Mean \pm SE & $28.68 \pm 1.76$ & $40.34 \pm 3.88^{*}$ & $31.32 \pm 2.95$ \\
\hline & & $\%$ of change & & +40.65 & +9.20 \\
\hline & 45 days & Mean \pm SE & $30.04 \pm 1.49$ & $41.2 \pm 2.41^{* *}$ & $35.66 \pm 1.94$ \\
\hline & & $\%$ of change & & +37.15 & +18.70 \\
\hline \multirow[t]{4}{*}{ Uric acid } & 30 days & Mean \pm SE & $5.2 \pm 0.374$ & $7.4 \pm 0.678^{* *}$ & $7.6 \pm 0.60^{* *}$ \\
\hline & & $\%$ of change & & +42.30 & +46.15 \\
\hline & 45 days & Mean \pm SE & $5.4 \pm 0.509$ & $13.4 \pm 1.69^{* *}$ & $11.4 \pm 1.12^{* *}$ \\
\hline & & $\%$ of change & & $+148.14 \%$ & $+111.11 \%$ \\
\hline
\end{tabular}

Significance difference between control and administrated groups. $n=5$ 


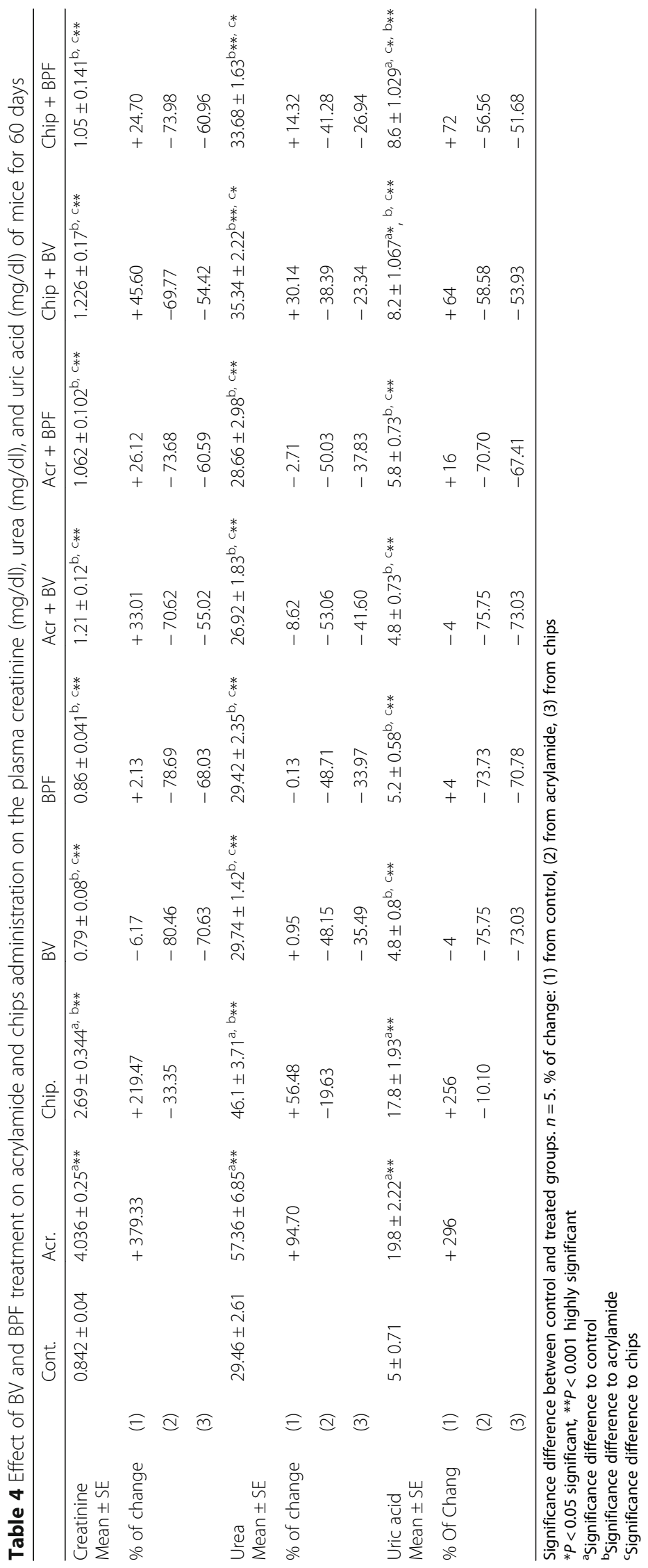


(2004). The significant increase in serum AST and ALT levels may be attributed to the bipolar nature of acrylamide where the $\mathrm{CH} 2=\mathrm{CH}$ part undergo hydrophobic interactions while the $\mathrm{CONH} 2$ part can form hydrogen bonds with the cell components (Chinoy \& Memon, 2001). This property of acrylamide enhances alteration in the cell membrane structure and makes the cell membrane of the liver more permeable of enzymes and appear first in the extracellular space and then in the blood. The toxicological effect of acrylamide is also attributed to adduct formation with the hepatic cell's DNA as reported by Dybing and Sanner (2003) that led to DNA strand breaks and dominant lethal mutation onset (Sega, Valdivia, Tancongco, \& Brimer, 1989; Ty, Friedman, Losco, \& Ross, 2000).

The present study elucidated a significant decrease of albumin levels in acrylamide-administered group that can be attributed to the leaking out of protein reserves from hepatocytes under the effect of higher doses of acrylamide or change in protein metabolism or retarded protein synthesis (Asha, Renu, \& Jyotsna, 2008). Also, acrylamide reacts with GSH and forms glutathione $S$-conjugates, which is the initial step in the biotransformation of electrophiles into mercapturic acids. Acrylamide is oxidized to glycidamide, a reactive epoxide, and undergoes conjugation with glutathione (Awad et al., 1998).

In the kidney, acrylamide- and chips-administered groups showed a time-dependent effect that results in the congestion of the capillary tuft of the glomeruli and necrosis of the epithelial cells of the kidney tubules that led to vacuolation and lost their brush borders. In this context, infiltration of inflammatory cells and periglomerular edema and vacuolar degenerative changes of kidney were reported in acrylamide intoxication (Eman \& Amany, 2008; Mansour, Ibrahim, El-Kholy, \& El-Madawy, 2008; Osman et al., 2016; Totani, Yawata, Ojiri, \& Fujioka, 2007). Moreover, continuous administration of acrylamide causes focal hemorrhages between the tubules at the corticomedullary junction that associated with focal fibrosis, degeneration, and swelling in the epithelial cells lining the tubules (Rawi et al., 2012). These findings may be attributed to the fact that kidneys are the main way of excretion of acrylamide and its metabolites which reach blood stream and extracted in the urine (Susan, Rodney, Wojciechl, Bahman, \& Timothy, 2003). The present investigation showed that administration of acrylamide induced some alterations in the serum creatinine, uric acid, and urea that were due to the pathological change in kidney tissue where acute ingestion of acrylamide causes impairment in renal function (Shelly, 1996).

The present study showed the protection of bee venom and its bradykinin-potentiating factor against the liver and nephrotoxicity, those induced with either acrylamide or chips administration at the levels of general histology, histochemistry, immunohistochemistry, and biochemical investigation. Bee venom and its bradykinin-potentiating factor protection against hepatoand nephrotoxicity were reported (Bekheeta, Awadallaa, Salmanb, \& Hassan, 2013; Darwish et al., 2013). Moreover, bee venom has a protective effect against impairment in liver and kidney tissues that is induced by gamma radiation where bee venom had significantly decreased the elevation of serum ALT, AST, and ALP (Elshater et al., 2014). The hepatoprotective effect of bee venom was attributed to inhibiting the secretion of pro-inflammatory cytokines and decreasing the elevated serum aminotransferase enzymes in different models of induced hepatic injury and nephrotoxicity (Hegazi, 2012; Hyunseong et al., 2013; Park et al., 2010).

The present investigation provoked upregulation of cytochrome $\mathrm{C}$ in the liver and kidney tissue of acrylamide at 30 and 45 days of experiments and chips-administered groups. Histological damage and immunosuppression of cytochrome $\mathrm{C}$ were recorded at 60 days of acrylamide administration. Bee venom or its bradykinin-potentiating factor seems to counteract the effect of acrylamide- or chips-administered groups regarding the immunohistochemistry of cytochrome C. Importance of cytochrome c arises from its involvement in apoptosis; the release of cytochrome $\mathrm{c}$ from mitochondria into the cytoplasm by various stimuli, triggering caspase activation through oxidation of cytosolic cytochrome $\mathrm{C}$ by mitochondrial cytochrome oxidase and the execution of apoptosis, is achieved (Brown \& Borutaite, 2008; Green, 2005; Martin et al., 2005; Twiddy et al., 2004). In healthy cells, cytosolic cytochrome $\mathrm{C}$ is rapidly reduced by various enzymes and/ or reductants which may function to block apoptosis (Brown \& Borutaite, 2008). It was shown that free Cytc functions as a radical scavenger by removing unpaired electrons from superoxide and it operates as a hydrogen peroxide scavenger (Korshunov, Krasnikov, Pereverzev, \& Skulachev, 1999; Pereverzev, Vygodina, Konstantinov, \& Skulachev, 2003; Wang, Li, Zhao, \& Xu, 2003).

\section{Conclusions}

The present investigation concluded the protective properties of bee venom and its extraction BPF against acrylamide- and chips-induced toxicity at the level of histopathology and physiology of the liver and kidney.

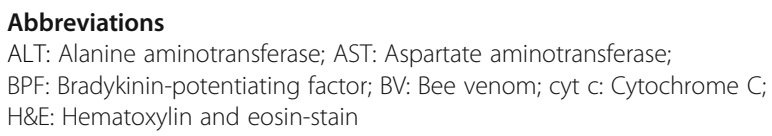

Availability of data and materials

The datasets generated and analyzed during the current study are available from the corresponding author on reasonable request. 


\section{Authors' contributions}

All authors suggested the study, participated in its design and coordination, interpret the results, and approved the final manuscript.

\section{Ethics approval}

This study was approved by the Social Science Ethical Committee of the Faculty of Science, Tanta University, and complied with the Egyptian Code of Conduct for Scientific Practice, National Research Centre, Egypt.

\section{Consent for publication}

Not applicable.

\section{Competing interests}

The authors declare that they have no competing interests.

\section{Publisher's Note}

Springer Nature remains neutral with regard to jurisdictional claims in published maps and institutional affiliations.

Received: 21 June 2018 Accepted: 18 September 2018 Published online: 26 September 2018

\section{References}

Abdel Hameed, T. F. (2004). Light and electron microscopic studies on the effect of orally administered formalin on liver and kidney of guinea pig. Journal of the Egyptian-German Society of Zoology, 45, 203-224.

Abdul-Hamid, M., \& Moustafa, N. A. (2005). Effect of ethanol administration on the liver and kidney of rat newborns at different conditions. Journal of the Egyptian-German Society of Zoology, 24, 267-294.

AL-Mosaibih, M. A. (2013). Effects of monosodium glutamate and acrylamide on the liver tissue of adult Wistar rats. Life Science Journal, 10(2s),35-42.

Alvarez-Fischer, D., Noelker, C., Vulinovic', F., Grunewald, A., Chevarin, C., Klein, C., .. Hartmann, A. (2013). Bee venom and its component apamin as neuroprotective agents in Parkinson disease in mouse model. PLoS One, 8(4), e61700.

Asha, S., Renu, S., \& Jyotsna, J. (2008). Biochemical changes in the liver of Swiss albino mice orally exposed to acrylamide. Maejo International Journal of Science and Technology, 2(03), 542-550.

Ashoor, S. H., \& Zent, J. B. (1984). Maillard browning of common amino acids and sugars. Journal of Food Science, 49, 1206-1207.

Awad, M. E., Abdel-Rahman, M. S., \& Hassan, S. A. (1998). Acrylamide toxicity in isolated rat hepatocytes. Toxicology In Vitro, 12, 699-704.

Barham, D., \& Trinder, P. (1972). Enzymatic colorimetric methods for determination of uric acid in serum plasma and urine. The Analyst, 97, 142-146.

Bekheeta, S. H. M., Awadallaa, E. A., Salmanb, M. M., \& Hassan, M. K. (2013). Prevention of hepatic and renal toxicity with bradykinin potentiating factor (BPF) isolated from Egyptian scorpion venom (Buthus occitanus) in gentamicin treated rats. Tissue and Cell, 45, 89-94.

Bekheeta, S. H. M., Awadallaa, E. A., Salmanb, M. M., \& Hassana, M. K. (2011). Bradykinin potentiating factor isolated from Buthus occitanus venom has a protective effect against cadmium-induced rat liver and kidney damage. Tissue and Cell, 43, 337-343.

Benziane, B., Bouras, D., Mezaini, A., Belhadri, A., \& Benali, M. (2018). Effect of oral exposure to acrylamide on biochemical and hematologic parameters in Wistar rats. Drug and Chemical Toxicology, 28, 1-10.

Brown, G. C., \& Borutaite, V. (2008). Regulation of apoptosis by the redox state of cytochrome c. Biochimica et Biophysica Acta, 1777(7-8), 877-881.

Buchlowalow, B. I., \& Bocker, W. (2010). Immunohistochemistry. Basics and methods. Berlin, Heidelberg: Springer Verlag.

Camargo, A., lanzer, D., Guerreiro, J. R., \& Serrano, S. M. (2012). Bradykininpotentiating peptides: Beyond captopril. Toxicon, 59, 516-523.

Chaney, A. L, Marbach, C. P., \& Fawectt, J. K. (1962). A colorimeteric method for determination of blood urea concentration. Journal of Clinical Chemistry, 8, 130-133.

Chen, J., \& Lariviere, W. R. (2010). The nociceptive and anti-nociceptive effects of bee venom injection and therapy: A double-edged sword. Progress in Neurobiology, 92, 151-183.

Cheville, N. F. (2009). Ultrastructural pathology: The comparative cellular basis of disease. (2nd ed., ). Wiley-Blackwell A john Wiley of Sons, Inc USA. 23, 154-178.

Chinoy, N. J., \& Memon, M. R. (2001). Beneficial effects of some vitamins and calcium on fluoride and aluminium toxicity of gastrocnemius muscle and liver of male mice. Fluoride, 34, 21-33.
Danneels, E. L., Van Vaerenbergh, M., Debyser, G., Devreese, B., \& de Graaf, D. C. (2015). Honeybee venom proteome profile of queens and winter bees as determined by a mass spectrometric approach. Toxins, 7, 4468-4483.

Darwish, S. F., El-Bakly, W. M., Arafa, H. M., \& El-Demerdash, E. (2013). Targeting TNFalpha and NF-kappa B activation by bee venom: Role in suppressing adjuvant induced arthritis and methotrexate hepatotoxicity in rats. PLoS One, 8, e79284.

Davis, L. N., Durkin, P. R., Howard, P. H., \& Saxena, J. (1976). Investigation of selected potential environmental contaminants: Acrylamide, EPA Technical Report, PB-257 (vol. 704, pp. 1-147).

Dearfield, K. L., Douglas, G. R., Ehling, U. H., Moore, M. M., Sega, G. A., \& Brusick, D. J. (1995). Acrylamide: A review of its genotoxicity and an assessment of heritable genetic risk. Mutation Research, 330, 71-99.

Dortaj, H., Anvari, M., Yadegari, M., Sharifabad, M. H., \& Sarcheshmeh, A. A. (2017). Stereological survey of the effect of vitamin $C$ on neonatal rat kidney tissue treated with acrylamide. Modern Medical Laboratory Journal, 1(2), 42-49.

Doumas, B. T., \& Biggs, H. G. (1976). Standard method of clinical chemistry, (p. 175). New York: Acad. Press.

Drury, R., \& Wallington, E. (1976). Carleton's histological technique, (pp. 48-58). London: Oxford University Press.

Dybing, E., \& Sanner, T. (2003). Risk assessment of acrylamide in foods. Toxicological Sciences, 75, 7-15.

El-Saadani, M. A. (2004). A scorpion venom peptide fraction induced prostaglandin biosynthesis in guinea pig kidneys: Incorporation of 14Clinoleic acid. The Biochemist, 135(1), 109-116.

Elshater, A. A., Mohi Eldin, M. M., Salman, M. M. A., \& Kasem, N. R. A. (2014). The curative effect of bee venom and propolis on oxidative stress induced by $\gamma$-irradiation on blood and tissues of rats. Egyptian Academic Journal of Biological Sciences, 6(1), 53-69.

Eman, M. A. E., \& Amany, Y. M. R. (2008). Some studies on acrylamide intoxication in male albino rats. Egyptian Journal of Comparative Pathology and Clinical Pathology, 21, 222-245.

Eriksson, S. (2005). Acrylamide in food products: Identification, formation and analytical methodology, PhD thesis, Department of Environmental Chemistry. Stockholm: Stockholm University.

Ferreira, S. H. (1965). A bradykinin-potentiating factor (Bpf) present in the venom of Bothrops jararaca. British Journal of Pharmacology, 24, 163-169.

Ferreira, S. H., Greene, L. H., Alabaster, V. A., Bakhle, Y. S., \& Vane, J. R. (1970). Activity of various fractions of bradykinin potentiating factor against angiotensin I converting enzyme. Nature, 225, 379-380.

Gajski, G., \& Garaj-Vrhovac, V. (2009). Radioprotective effects of honey bee venom (Apis mellifera) against 915-MHz microwave radiation induced DNA damage in Wistar rat lymphocytes: In vitro study. International Journal of Toxicology, 28(2), 88-98.

Gamboa da Costa, G., Churchwell, M. I., Hamilton, L. P., von Tungeln, L. S., Beland, F. A., Marques, M. M., \& Doerge, D. R. (2003). DNA adduct formation from acrylamide via conversion to glycidamide in adult and neonatal mice. Chemical Research in Toxicology, 16, 1328-1337.

Green, D. R. (2005). Apoptotic pathways: Ten minutes to dead. Cell, 121, 671-674.

Guo, L. Y., Zhu, J. F., \& Wu, X. F. (1999). Cloning of a cDNA encoding a nerve growth factor precursor from the Agkistrodon halys Pallas. Toxicon, 37, 465-470.

Hegazi, A. G. (2012). Medical importance of bee products. U. Arı Drg. Kasım Bee J, $12(4), 136-146$.

Husdan, H., \& Rapoport, A. (1968). Estimation of creatinine by the Jaffe reaction. A comparison of three methods. Clinical Chemistry, 14(3), 222-238.

Hyunseong, K., Gihyun, L., Soojin, P., Hwan-Suck, C., Hyojung, L., Jong-Yoon, K., ... Hyunsu, B. (2013). Bee venom mitigates cisplatin-induced nephrotoxicity by regulating $\mathrm{CD} 4(+) \mathrm{CD} 25(+)$ Foxp3(+) regulatory T cells in mice. Evidencebased Complementary and Alternative Medicine, 2013, 1-10.

IARC (International Agency for Research on Cancer) (1994). Some industrial chemicals, IARC Monogr. Eval. Carcinog. Risk Chem. Hum, 60, 389-433.

Jain, R. K. (2003). Molecular regulation of vessel maturation. Nature Medicine, 9, 685-693.

Jang, H. S., Chung, H. S., Ko, E., Shin, J. S., Shin, M. K., Hong, M. C., et al. (2009). Microarray analysis of gene expression profiles in response to treatment with bee venom in lipopolysaccharide activated RAW 264.7 cells. Journal of Ethnopharmacology, 121, 213-220.

Javad, B., Adeleh, D., \& Ali, A. S. (2014). Honey bee venom decreases the complications of diabetes by preventing hemoglobin glycation. Journal of Molecular Liquids, 199, 371-375.

Khalil, W. K. B., Assaf, N., ElShebiney, S. A., \& Salem, N. A. (2015). Neuroprotective effects of bee venom acupuncture therapy against rotenone-induced oxidative stress and apoptosis. Neurochemistry International, 80, 79-86. 
Korshunov, S. S., Krasnikov, B. F., Pereverzev, M. O., \& Skulachev, V. P. (1999). The antioxidant functions of cytochrome C. FEBS Letters, 462, 192-198.

Lee, K. G., Cho, H. J., Bae, Y. S., Park, K. K., Choe, J. Y., Chung, I. K., et al. (2009). Bee venom suppresses LPS-mediated NO/iNOS induction through inhibition of PKC-alpha expression. Journal of Ethnopharmacology, 123, 15-21.

Lewis, R. J., \& Garcia, M. L. (2003). Therapeutic potential of venom peptides. Nature Reviews. Drug Discovery, 2, 790-802.

Lipps, B. V. (1998). Biological and immunological properties of nerve growth factor from snake venom. Journal of Natural Toxins, 7, 121-130.

Machado, R. A., Junior, L. G. M., Monteiro, N. K. V., Silva-Júnior, A. A., Portaro, F. C. V., Barbosa, E. G., ... Fernandes-Pedrosa, M. (2015). Homology modeling, vasorelaxant and bradykinin-potentiating activities of a novel hypotensin found in the scorpion venom from Tityus stigmurus. Toxicon, 101, 11-18.

Mahmood, S. A. F., Amin, K. A. M., \& Salih, S. F. M. (2015). Effect of acrylamide on liver and kidneys in albino Wistar rats. International Journal of Current Microbiology and Applied Sciences, 4(5), 434-444.

Mansour, M. K., Ibrahim, E. M., El-Kholy, M. M., \& El-Madawy, S. A. (2008). Antioxidant and histopathological effect of catechin and neem leaves extract in acrylamide toxicity of rats. Egyptian Journal of Comparative Pathology and Clinical Pathology, 21, 290-313.

Martin, M. C., Allan, L. A., Lickrish, M., Sampson, C., Morrice, N., \& Clarke, P. R. (2005). Protein kinase A regulates caspase- 9 activation by Apaf-1 downstream of cytochrome c. The Journal of Biological Chemistry, 280, 15449-15455.

Meki, A., \& Omar, H. E. (1997). A bradykinin potentiating fraction isolated from the venom of Egyptian scorpion Buthus occitanus induced prostaglandin biosynthesis in female guinea pigs. Comparative Biochemistry and Physiology, 116, 183-189.

Moustafa, N. A., \& Abdul-Hamid, M. (2007). Protective effect of phytic acid against the microscopical changes induced by aflatoxin B1 in the liver and kidney of white rats. Journal of the Egyptian-German Society of Zoology, 53, 1-27.

Nassar, A. Y., Abu-Sinna, G., \& Abdel Rahim, S. (1990). Effect of bradykinin potentiating fraction from venom of the Egyptian scorpion, Buthus occitanus on the ovarian and endometrium of mice. Toxicon, 28, 525-534.

Nassar, A. Y., Abu-Sinna, G., Abdel Rahim, S., Soliman, M., \& El-Saadani, M. (1992). Bradykinin potentiating fraction isolated from venom of Buthus occitanus promotes spermatogenesis in premature mice. Rec. Advance Toxinol. Research, 2, 119-135.

Needelman, P., Marshall, G., \& Sahel, B. E. (1975). Hormones interactions in the isolated rabbit heart: Synthesis and coronary vasomotor effects of prostaglandins, angiotensin and bradykinin. Circulation Research, 37, 802-808.

Orśolić, N. (2012). Bee venom in cancer therapy. Cancer Metastasis Reviews, 31 , 173-194.

Osman, M. A., Romeilah, R. M., Elgammal, M. H., Ramis, E. S., \& Hasan, R. S. (2016), Subchronic toxicity of acrylamide in fried rice and preventive effect of grape leaves. Asian Journal of Biochemistry, 11(2), 68-81.

Pari, L., \& Murugan, P. (2004). Protective role of tetrahydrocurcumin against erythromycin estolate induced hepatotoxicity. Pharmacological Research, 49, 481-486.

Park, J. H., Kim, K. H., Kim, S. J., Lee, W. R., Lee, K. G., \& Park, K. K. (2010). Bee venom protects hepatocytes from tumor necrosis factor-alpha and actinomycin D. Archives of Pharmacal Research, 33(2), 215-223.

Pereverzev, M. O., Vygodina, T. V., Konstantinov, A. A., \& Skulachev, V. P. (2003) Cytochrome c, an ideal antioxidant. Biochemical Society Transactions, 31 1312-1315

Rawi, S. M., Marie, M. A., Fahmy, S. S. R., \& El-Abied, S. A. (2012). Hazardous effects of acrylamide on immature male and female rats. African Journal of Pharmacy and Pharmacology, 6, 1367-1386.

Reitman, S., \& Frankel, S. (1957). A colorimetric method for the determination of serum glutamic oxalacetic and glutamic pyruvic transaminases. American Journal of Clinical Pathology, 28(1), 56:63.

Rice-Evans, C., \& Burdon, R. (1993). Free radical-lipid interactions and their pathological consequences. Progress in Lipid Research, 32, 71-110.

Roberts, R. A. (1989). Bradykinin receptors: Characterization, distribution and mechanisms of signal transduction. Progress in Growth Factor Research, 1, 237-252.

Salman, M.M.A. (1995). Effect of a bradykinin potentiating factor isolated from scorpion venom, Buthus occitanus on burnt skin of Guinea pig in comparison with other drugs. M.Sc. Thesis, Faculty of Science, Ain Shams University.

Sega, G. A., Valdivia, R. P., Tancongco, C. P., \& Brimer, P. (1989). Acrylamide binding to the DNA and protamine of spermiogenic stages in the mouse and its relationship to genetic damage. Mutation Research, 216, 221-230.
Seo, S., Jung, W., Lee, S., Choi, C., Shin, B., Kim, E., ... Park, S. (2008). Effects of bee venom on cholecystokinin octapeptide $Y$ induced acute pancreatitis in rats. Pancreas, 36(2), 22-29.

Shelly, (1996). Regina vs. Calder. Transcript records of New Zealand High Court, Christchurch, New Zealand.

Shrivastava, S., Uthra, C., Salim Reshi, M., Singh, A., Yadav, D., \& Shukla, S. (2018). Protective effect of hesperetin against acrylamide induced acute toxicity in rats. Indian The Journal of Experimental Biology,56: 164-170

Siahkoohi, S., Anvari, M., Tafti, M. A., \& Sharifabad, M. H. (2014). The effects of vitamin $\mathrm{E}$ on the liver integrity of mice fed with acrylamide diet. Iranian Journal of Pathology, 9(2), 89-98.

Sipes, I. G., \& Carter, D. E.(1981). Pharmakinetics of xenobiotics: Acrylamide. NIEHS Contract No. 1- ES-8-2130.

Smith, E. A., \& Oehme, F. W. (1991). Acrylamide and polyacrylamide: A review of production, use, environmental fate and neurotoxicity. Reviews on Environmental Health, 9, 215-228.

Son, D. J., Lee, J. W., Lee, Y. H., Song, H. S., Lee, C. K., \& Hong, J. T. (2007). Therapeutic application of antiarthritis, pain-releasing, and anti-cancer effects of bee venom and its constituent compounds. Pharmacology and Therapeutics, 115(2), 246-270.

Sonveaux, P. (2008). Provascular strategy: Targeting functional adaptations of mature blood vessels in tumors to selectively influence the tumor vascular reactivity and improve cancer treatment. Radiotherapy and Oncology, 86, 300-313.

Susan, C. J., Rodney, W. S., Wojciechl, K., Bahman, A., \& Timothy, R. F. (2003). Acrylamide: A comparison of metabolism and hemoghobin adducts in rodents following, dermal, intraperitoneal, oral, or inhalation exposure. Toxicological Sciences, 75, 260-270.

Törnqvist, M. (2005). Acrylamide in food: The discovery and its implications. In Chemistry and Safety of Acrylamide in Food, See Friedman Mottram, (pp. 1-19).

Totani, N., Yawata, M., Ojiri, Y., \& Fujioka, Y. (2007). Effects of trace acrylamide intake in Wistar rats. Journal of Oleo Science, 56, 501-506.

Tu, W. C., Wu, C. C., Hsieh, H. L., Chen, C. Y., \& Hsu, S. L. (2008). Honeybee venom induces calcium dependent but caspase-independent apoptotic cell death in human melanoma A2058 cells. Toxicon, 52, 318-329.

Twiddy, D., Brown, D. G., Adrain, C., Jukes, R., Martin, S. J., Cohen, G. M., ... Cain, K. (2004). Pro-apoptotic proteins released from the mitochondria regulate the protein composition and caspase-processing activity of the native Apaf-1/caspase9 apoptosome complex. The Journal of Biological Chemistry, 279, 19665-19682.

Ty, R. W., Friedman, M. A., Losco, P. E., \& Ross, W. P. (2000). Rat two-generation reproduction and dominant lethal study of acrylamide in drinking water. Reproductive Toxicology, 14, 385-401.

Verano-Braga, T., Figueiredo-Rezende, F., Melo, M. N., Lautner, R. Q., Gomes, E. R. M., Mata-Machado, L. T., ... Pimenta, A. M. C. (2010). Structure-function studies of Tityus serrulatus Hypotensin-I (TsHpt-I): A new agonist of B(2) kinin receptor. Toxicon, 56, 1162-1171.

Wang, Z. B., Li, M., Zhao, Y., \& Xu, J. X. (2003). Cytochrome $C$ is a hydrogen peroxide scavenger in mitochondria. Protein and Peptide Letters, 10, 247-253.

WHO (World Health Organization) (2005). Summary report of the sixty-fourth meeting of the joint FAONHO expert committee on food additive (JECFA), (pp. 1-47). Washington, DC: Rome, Italy: The ILSI Press International Life Sciences Institute.

Yoon, M., \& Lee, D. (2013). Investigation of the neuroprotective effects of beevenom acupuncture in a mouse model of Parkinson's disease by using immunohistochemistry and In-vivo $1 \mathrm{H}$ magnetic resonance spectroscopy at 9.4 T. Journal Korean Physical Society, 62(2), 320-327.

Yousef, M. I., \& El-Demerdash, F. M. (2006). Acrylamide-induced oxidative stress and biochemical perturbations in rats. Toxicology, 219, 133-141. 